\section{La medición de la corrección del tratamiento de la bacteriemia}

\section{Sr. Director:}

El trabajo sobre los factores pronósticos de la bacteriemia, recientemente publicado en Anales de Medicina Interna (1), encuentra que en los casos con un tratamiento antibiótico inadecuado el riesgo relativo (RR) de muerte es 6 (ó 6,7 según el resumen del estudio). Pero no queda claro si la medición de la adecuación del tratamiento se hizo sin conocer el resultado final de la enfermedad. Sabiendo que se ha curado un episodio de bacteriemia, es difícil afirmar que la dosis, la vía de administración o la duración del tratamiento fueron inadecuadas; mientras que lo contrario sucede tras el fallecimiento del paciente a causa de la enfermedad. Por tanto, la medición "no ciega" de la variable "corrección del tratamiento" no es válida. Por otra parte, si esta variable se hubiera medido antes del desenlace de la enfermedad, como parece deducirse de que en el título del trabajo figure la expresión "estudio prospectivo", se plantearía el problema ético de qué hacer cuando se detecta un tratamiento incorrecto o, incluso, la ausencia de tratamiento ( $9 \%$ de los pacientes en general y $18 \%$ de ellos en el área quirúrgica); parece que en esos casos, en interés del paciente, habría que tratar de corregir esa incorrección lo antes posible y, aunque ello no siempre se consiguiera, ya no se podría estudiar el efecto del tratamiento, pues el grupo de pacientes con antibióticos inadecuados sería especial en algunos sentidos (por ejemplo: fallecimiento muy precoz, negativa del médico responsable a modificar el tratamiento, etc.). En definitiva, como la forma de medir el factor "corrección del tratamiento" y el enfoque ético que la justifica no están claros, la cifra de RR que los autores aportan no es válida. En vista de lo anterior, tiene una importancia menor el que no conste el intervalo de confianza de ese RR (ni, dicho sea de paso, de ningún otro), a pesar de que en la sección sobre el método estadístico se afirma que se utilizó tanto la estimación puntual como el intervalo de confianza.

Que el tratamiento antibiótico adecuado es curativo en esta enfermedad es algo conocido; en el trabajo que se ha comentado constan referencias bibliográficas que apoyan esta afirmación. Sin embargo, por los motivos mencionados, si ese estudio fuese la única investigación sobre la materia no podría confiarse en la utilidad de los antibióticos para el tratamiento de la bacteriemia.

\section{R. Cuena Boy}

Unidad de Farmacología Clínica (Servicio de Medicina Interna). Hospital Virgen de la Salud de Toledo

1. Pazos Añón R, Fernández Rodríguez R, Paz Vidal I, Tinajas A, Cantón I, Abel V, González R, Martínez R, Gayoso P, Fernández Âlvarez O. Factores pronósticos de la bacteriemia: estudio prospectivo. An Med Interna (Madrid) 2001; 18: 415-420.

\section{Sr. Director:}

En referencia a los comentarios del Dr. Rafael Cuena Boy en "La medición de la corrección del tratamiento de la bacteriemia" (1), queremos realizar las siguientes matizaciones:

- Como se apunta en varios trabajos referenciados en la bibliografía de nuestro Original hay cierto consenso en considerar el tratamiento antibiótico adecuado (apropiado) cuando se demostró su actividad in vitro frente al o los microorganismos aislados y se administró a dosis correctas y por vías correctas durante un período de tiempo no inferior a los 7 días. Cuando se emplearon asociaciones de antibióticos se consideró tratamiento antibiótico apropiado cuando al menos uno de estos antibióticos era activo in vitro frente al o los microorganismos aislados $(2,3)$.

- La definición de tratamiento antibiótico adecuado o inadecuado en los enfermos de nuestro estudio prospectivo (4) incluyó y se refirió al tratamiento antibiótico empírico inicial, previo a conocer el agente microbiológico causal y el antibiograma. Con el resultado del hemocultivo, el clínico y microbiólogo implicados estimaban la bacteriemia como verdadera o no y, por supuesto, interveníamos de inmediato en adecuar el tratamiento antibiótico en caso de que fuese incorrecto. No hemos tenido ningún caso de negativa del médico responsable del enfermo a la modificación del tratamiento antibiótico indicada; tres pacientes solicitaron el alta voluntaria y rechazaron completar el tratamiento que fue considerado inadecuado. Si el paciente moría antes de recibirse el resultado del antibiograma los datos se incluían y categorizaban según estos criterios de adecuado o inadecuado. Cuando el paciente no recibía tratamiento antibiótico al informarse el hemocultivo: lo consideramos "apropiado" si el aislamiento era un contaminante, también "apropiado" si el episodio se consideró que representaba una bacteriemia o fungemia transitoria resuelta (confirmado tras un adecuado seguimiento), y se consideró "inapropiado" si el hemocultivo representaba verdadera bacteriemia procediéndose a instaurar el tratamiento de acuerdo con su médico responsable. Pensamos por tanto que sobra cualquier duda sobre la ética en el proceder de este trabajo original

-Tras el análisis de nuestra situación después de realizar el estudio original publicado en su revista (4) y la identificación del problema de la inadecuación del tratamiento (fundamentalmente empírico) hemos procedido a medidas que mejoren la política antibiótica general y a consolidar las Consultas de Infecciosas; en un estudio actualmente en marcha valoraremos los resultados de esta intervención.

\section{R. Pazos Añón}

1. Cuena Boy R. La medición de la corrección del tratamiento de la bacteriemia. An Med Interna (Madrid) 2002; 19: 383.

2. Grupo de estudios de la bacteriemia. Bacteriemia en seis hospitales espanoles. Med Clin ( Barc) 1986;86:221-232

3. Weinstein MP, Towas ML, Quartey SM, Mirret S, Reimer LG, Parmigiani $\mathrm{G}$ et al. The clinical significance of positive blood cultures in the 1990s: a prospective comprehensive evaluation of the microbiology,epidemiology and outcome of bacteriemia and fungemia in adults. Clin Infect Dis 1997;24:584-602

4. Pazos Añón R, Fernández Rodríguez R, Paz Vidal I, Tinajas A, Cantón I, Abel V, González R, Martínez R, Gayoso P, Fernández Alvarez O. Factores pronósticos de la bacteriemia: estudio prospectivo. An Med Interna (Madrid) 2001;18:415-420.

\section{Alcalosis metabólica severa por ingesta de bicarbonato}

\section{Sr. Director:}

La intoxicación por bicarbonato oral es poco frecuente y sus consecuencias engloban alteraciones fundamentalmente del sistema nervioso central, cardiopulmonar y electrolíticas. Presentamos un caso de alcalosis metabólica severa por ingesta crónica de grandes cantidades de bicarbonato sódico.

En presencia de una adecuada respuesta respiratoria la alcalosis metabólica severa supone una concentración de bicarbonato en plasma mayor de $45 \mathrm{mmol} / \mathrm{litro}$. Las causas más frecuentes son las pérdidas de ácido gástrico y la toma de diuréticos de asa y tiazídicos $(1,2)$. Sin embargo y a pesar de que el bicarbonato 
sódico ha sido ampliamente utilizado, son escasos los casos documentados de alcalosis metabólica severa por ingesta de grandes dosis de bicarbonato sódico.

Varón de 65 años de edad con antecedentes de hepatopatía enólica, fumador importante y consumidor habitual de cantidades importantes de bicarbonato por dispepsia ulcerosa (según consta en historia de urgencias "vive solo y abandonado al alcohol, tabaco, bicarbonato y no comer" La familia refería el consumo de bicarbonato "por botes e incluso mezclado con alcohol"). Ingresa por cuadro de agitación psicomotriz y desorientación de 48 horas de evolución. A la exploración el paciente estaba descuidado y desnutrido, obnubilado con leguaje incoherente. Apirético y hemodinámicamente estable. Auscultación cardio-respiratoria con disminución generalizada del murmullo vesicular por hipoventilación. Abdomen globuloso, no doloroso y con ascitis en flancos. Analíticamente destacaba una alcalosis metabólica con $\mathrm{pH}$ inicial de 7,58 y bicarbonato plasmático de $57,4 \mathrm{mmol} / \mathrm{l}$. Como consecuencia del trastorno metabólico también presentó un potasio inicial de $1,7 \mathrm{mEq} / \mathrm{l}$ con signos electrocardiográficos de hipopotasemia, una insuficiencia respiratoria global con $\mathrm{pO}_{2}$ de $43 \mathrm{~mm} \mathrm{Hg}$ y $\mathrm{pCO}_{2}$ de $60 \mathrm{~mm}$ $\mathrm{Hg}$ y cierto grado de rabdomiolisis con CPK de 2.780. En la tabla I resumimos la evolución de algunos de los parámetros analíticos. Se repuso potasio al mismo tiempo que se administró oxigeno por la insuficiencia respiratoria global. Acetazolamida y aldosterona dada la existencia de un tercer espacio y ranitidina para disminuir las pérdidas digestivas. Los parametros se normalizaron a las 72 horas no siendo necesaria la administración de hidroxiclorico intravenoso.

TABLA I

EVO LUCIÓN DE LOS PARÁM ETROS BIO Q UÍMICOS MONITORIZADOS

\begin{tabular}{lcccc}
\hline & $\begin{array}{c}\text { Parámetros } \\
\text { al ingreso }\end{array}$ & $\begin{array}{c}\text { A las 16 } \\
\text { horas }\end{array}$ & $\begin{array}{c}\text { A las 48 } \\
\text { horas }\end{array}$ & $\begin{array}{c}\text { A las 72 } \\
\text { horas }\end{array}$ \\
\hline $\begin{array}{l}\mathrm{pH} \\
\mathrm{HCO} \\
\left(\mathrm{mmol}_{3} / \mathrm{l}\right)\end{array}$ & 57,4 & 7,60 & 7,48 & 7,46 \\
$\mathrm{PO}_{2}$ & 43 & 53,6 & 40 & 35 \\
$(\mathrm{~mm} \mathrm{Hg})$ & & 36 & $\begin{array}{c}30 \\
\text { (sangre venosa) }\end{array}$ & 59,7 \\
$\begin{array}{l}\mathrm{PCO}_{2} \\
(\mathrm{~mm} H \mathrm{Hg})\end{array}$ & 60 & 54 & 53 & 49 \\
$\begin{array}{l}\text { Sodio } \\
\text { (mEq/l) }\end{array}$ & 137 & 134 & 141 & 145 \\
$\begin{array}{l}\text { Potasio } \\
\text { (mEq/l) }\end{array}$ & 1,7 & 2,1 & 2,3 & 3,4 \\
\hline
\end{tabular}

El bicarbonato sódico es un agente clásico y de amplio uso en la dispepsia ulcerosa. Los riesgos de su ingesta excesiva, tanto agudas como crónicas incluyen la alcalosis metabólica, la hipokaliemia, hipernatremia, hipoxemia e hipercapnia. Sin embargo se han descrito en la literatura muy pocos casos de trastornos metabólicos severos por ingesta de bicarbonato3-6.

La alcalemia con un $\mathrm{pH}>7,60$, tanto metabólica como la producida por el síndrome de hiperventilación, conlleva un alto riesgo de hipoperfusión cerebral y miocárdico, especialmente en pacientes con cardiopatía de base. Las alteraciones neurológicas incluyen la aparición de cefalea, tetania, convulsiones, letárgia, delirio y estupor. Asimismo la depresión respiratoria, con hipoxemia e hipercapnia es más patente en enfermos con alteraciones ventilatorias previas. La alcalosis metabólica también predispone a arritmias supraventriculares y ventriculares refractarias. El trastorno electrolítico más frecuente y que perpetúa la alcalemia es la hipopotasemia principalmente en las alcalosis de origen metabólico. Las causa de esta hipokaliemia frecuentemente severa son la entrada de potasio en las células y pérdidas tanto renales como extrarrenales. A su vez dicha hipopotasemia favorece la aparición de arritmias, la debilidad muscular y aumenta el riesgo de encefalopatía hepática $(1,2)$.

En cuanto al tratamiento de la alcalosis metabólica el objetivo inicial es lograr un $\mathrm{pH}<7,55$ y un bicarbonato en plasma $<40 \mathrm{mEq} / \mathrm{l}$. El primer paso a realizar es eliminar las causas que lo están produciendo bien sea evitando los vómitos (con el uso de antieméticos), utilizando inhibidores de la bomba de protones o antiH2 (sobre todo si es debido a un drenaje gástrico), disminuyendo o retirando los diuréticos tiazidicos o de asa o añadiendo diuréticos ahorradores de potasio (espironolactona) o como en nuestro caso discontinuando el aporte de sustancias alcalóticas. Además de ello se debe realizar reposición hidroelectrolítica (volumen, cloruros sódico y potásico). Es necesario extremar las precauciones en el manejo del potasio ya que al corregirse la alcalosis, y sobre todo si se hace de forma muy rápida, se produce la salida de potasio del espacio intra al extracelular, lo que puede provocar una hiperpotasemia de rebote. En aquellos pacientes con un tercer espacio como era nuestro caso, se benefician de tratamiento diurético con acetazolamida (inhibidor de la anhidrasa carbónica) y diuréticos ahorradores de potasio (2,7). En algunas ocasiones es necesario corregir la alcalosis de forma rápida, estando indicado entonces el uso de ácidos a través de una vía central (por sus propiedades esclerosantes).

En conclusión, el bicarbonato sódico es un agente ampliamente usado, no exento de complicaciones si su ingesta es descontrolada como en nuestro caso. Generalmente los pacientes no lo consideran un medicamento y por tanto hay que preguntar específicamente su consumo cuando evaluamos una alcalosis metabólica. No obstante se necesita un consumo crónico y excesivo para llegar a la situación que hemos descrito. El tratamiento además de interrumpir el consumo, está dirigido a controlar los trastornos hidroelectrolíticos asociados y las complicaciones cadio-respiratorias.

L. León-Ruiz, C. Hidalgo Tenorio, N. Díaz-Ricomá, G. Piédrola Maroto*, M. López Gómez

Servicio de Medicina Interna y *Servicio de Endocrinología. Hospital Virgen de las Nieves. Granada

1. Adrogué HJ, Madias NE. Medical Progress: Management of Life-Threatening Acid-Base Disorders. N Engl J Med. 1998; 338: 26-34.

2. Adrogué HJ, Madias NE. Medical Progress: Management of Life-Threatening Acid-Base Disorders. N Engl J Med. 1998; 338: 107-111.

3. Mennen M, Slovis CM. Severe metabolic alkalosis in the emergency department. Ann Emerg Med. 1988; 17: 354-357.

4. Thomas SH, Stone CK. Acute toxicity from baking soda ingestion. Am J Emerg Med 1994; 12: 57-59.

5. Okada K, Kono N, Kobayashi S, Yamaguchi S. Metabolic alkalosis and myoclonus from antacid ingestion. Intern Med. 1996; 35: 515-516.

6. Fitzgibbons LJ, Snoey ER. Severe metebolic alkalosis due to baking soda ingestion: case reports of two patients with unsuspected antacid overdose. J Emerg Med. 1999;17: 57-61.

7. Díaz R, Mon C, García MP. Trastornos de equilibrio ácido-base. En: M.S. Acedo, A. Barrios, R. Díaz, S. Orche, R.M. Sanz. Manual de diagnóstico y terapéutica médica 4a edición. Madrid 1998. 